\title{
Reply to: Caution over the use of ecological big data for conservation
}

https://doi.org/10.1038/s41586-021-03464-9

Received: 14 February 2021

Accepted: 16 March 2021

A

Check for updates
Our global analysis ${ }^{1}$ estimated the overlap and fishing exposure risk (FEI) using the space use of satellite-tracked sharks and longline fishing effort monitored by the automatic identification system (AIS). In the accompanying Comment, Harry and Braccini ${ }^{2}$ draw attention to two localized shark-longline vessel overlap hotspots in Australian waters, stating that 47 fishing vessels were misclassified as longline and purse seine vessels in the Global Fishing Watch (GFW) ${ }^{3}$ 2012-2016 AIS fishing effort data product that we used. This, they propose ${ }^{2}$, results in misidentifications that highlight fishing exposure hotspots that are subject to an unexpected level of sensitivity in the analysis and they suggest that misidentifications could broadly affect the calculations of fishing exposure and the central conclusions of our study ${ }^{1}$. We acknowledged in our previously published paper ${ }^{1}$ that gear reclassifications were likely to occur for a small percentage of the more than 70,000 vessels studied, however, here we demonstrate that even using much larger numbers of vessel reclassifications than those proposed by Harry and Braccini ${ }^{2}$, the central results and conclusions of our paper ${ }^{1}$ do not change.

In our use of a third-party dataset such as GFW ${ }^{3}$, we stated clearly ${ }^{1}$ that the dataset is undergoing continuous refinement to correct for acknowledged contamination of some gear types with others in some regions (for example, drifting longlines with bottom-set longlines off New Zealand ${ }^{1}$ ). The characterization of GFW vessels (gear) is undertaken using two convolutional neural networks that were trained ${ }^{3}$ on 45,441 marine vessels (fishing and non-fishing) that identified six 


\section{Matters arising}
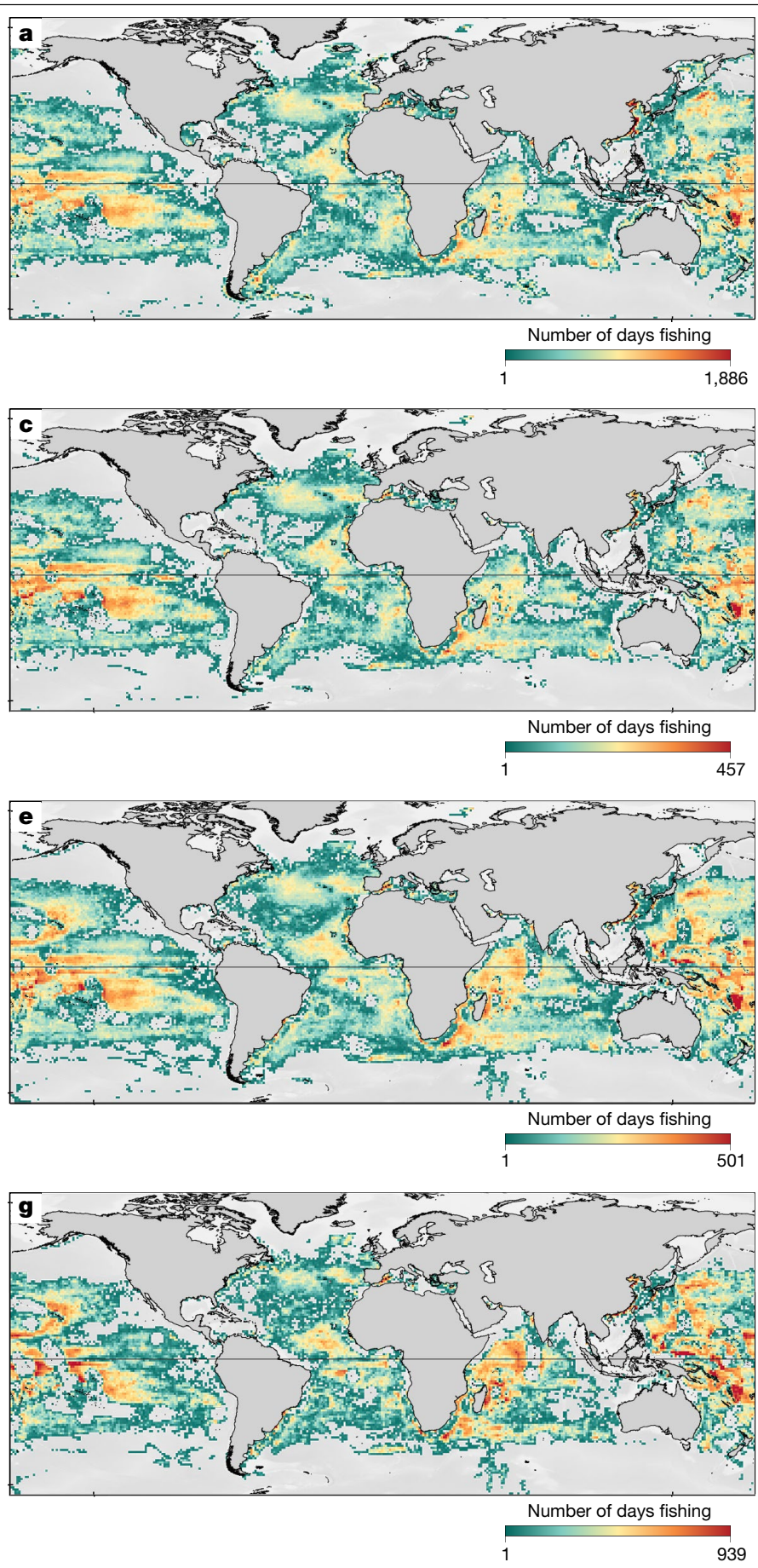

Fig. 1 Comparing AIS longline fishing datasets. a-h, Comparison of GFW data of AIS longline fishing effort (a, c, e, g; fishing days, where 1 day $=24 \mathrm{~h}$ fishing effort) and spatial overlap intensity (FEI) with pelagic sharks (b, d, f, h) for three GFW datasets of longline fishing effort and Queiroz et al. ${ }^{1}$. The original 2012-2016 AIS longline fishing effort and FEI $(\mathbf{a}, \mathbf{b})$ was compared with

classes of fishing vessels and six classes of non-fishing vessels with 95\% accuracy, as stated in our paper ${ }^{1}$. It is inevitable, therefore, that for some of the more than 70,000 AIS-monitored fishing vessels analysed, the gear was misclassified. Fortunately, a growing number of nations now maintain publicly accessible, online vessel registries to promote transparency and science within the fishing sector. For example, the European Union (EU) releases identifying information (including vessel name, identification numbers and fishing gear) for all fishing vessels registered to any EU country ${ }^{4}$. This eliminates the need to develop and
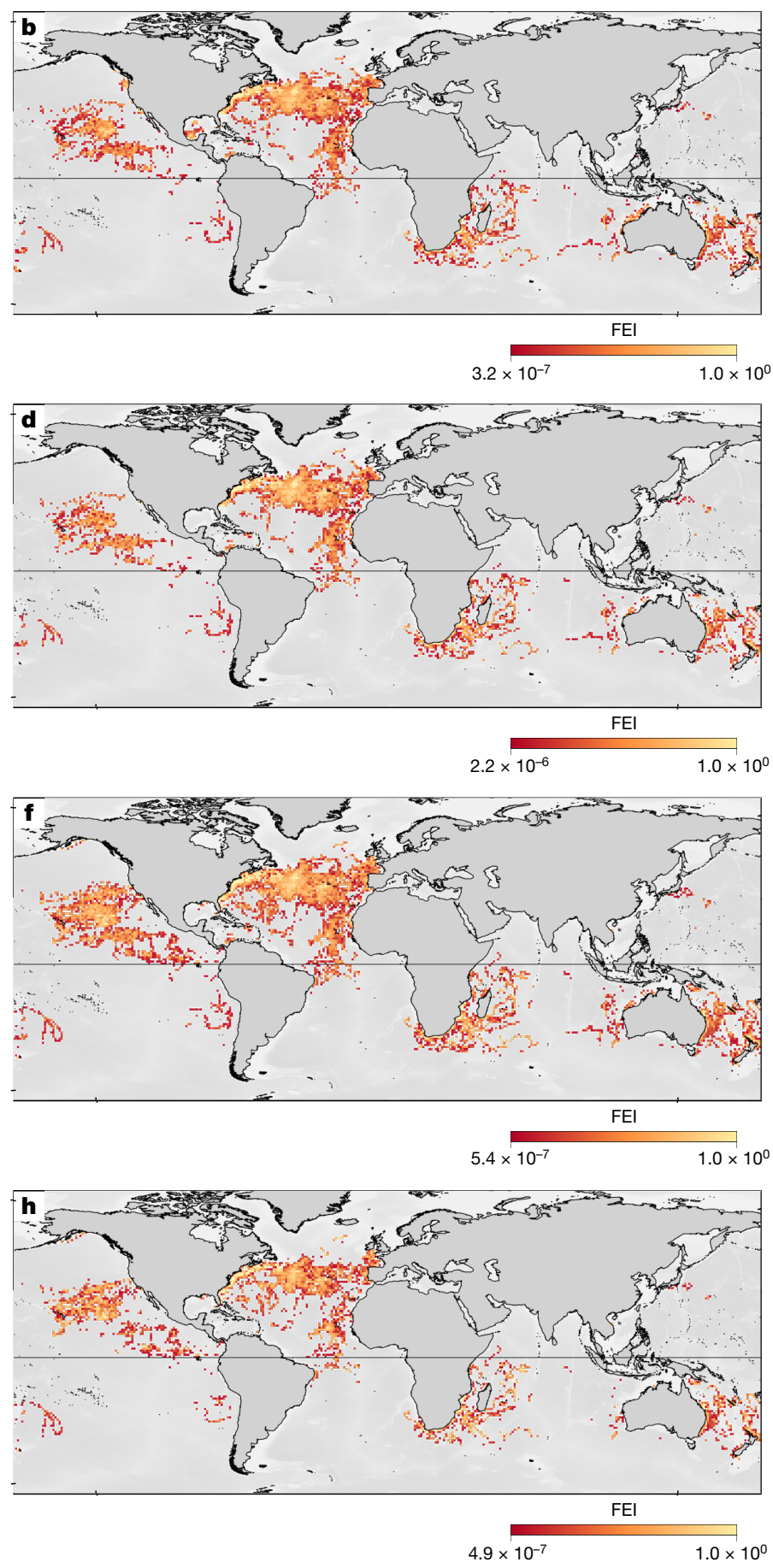

the new data releases of GFW fishing effort for 2012-2016 (c, d), 2012-2018 (e,f) and 2018 only $(\mathbf{g}, \mathbf{h})$. These analyses show minor global differences across the datasets even in the light of improvements in gear characterization algorithms and further verification with additional fishing vessel metadata.

refine models to estimate this information, as was the case for most of the vessels that we analysed. For countries that have not adopted this practice, including Australia, models provide necessary estimates in lieu of official information.

Since the publication of our paper ${ }^{1}$ there have been further improvements, including the recent data of AIS longline fishing effort for 2018 with updated gear assignments based on convolutional neural networks and data for more vessels. Mapping the new data (Fig. 1) shows that, indeed, the fishing effort by 12 vessels in Australia's Northwest Shelf 

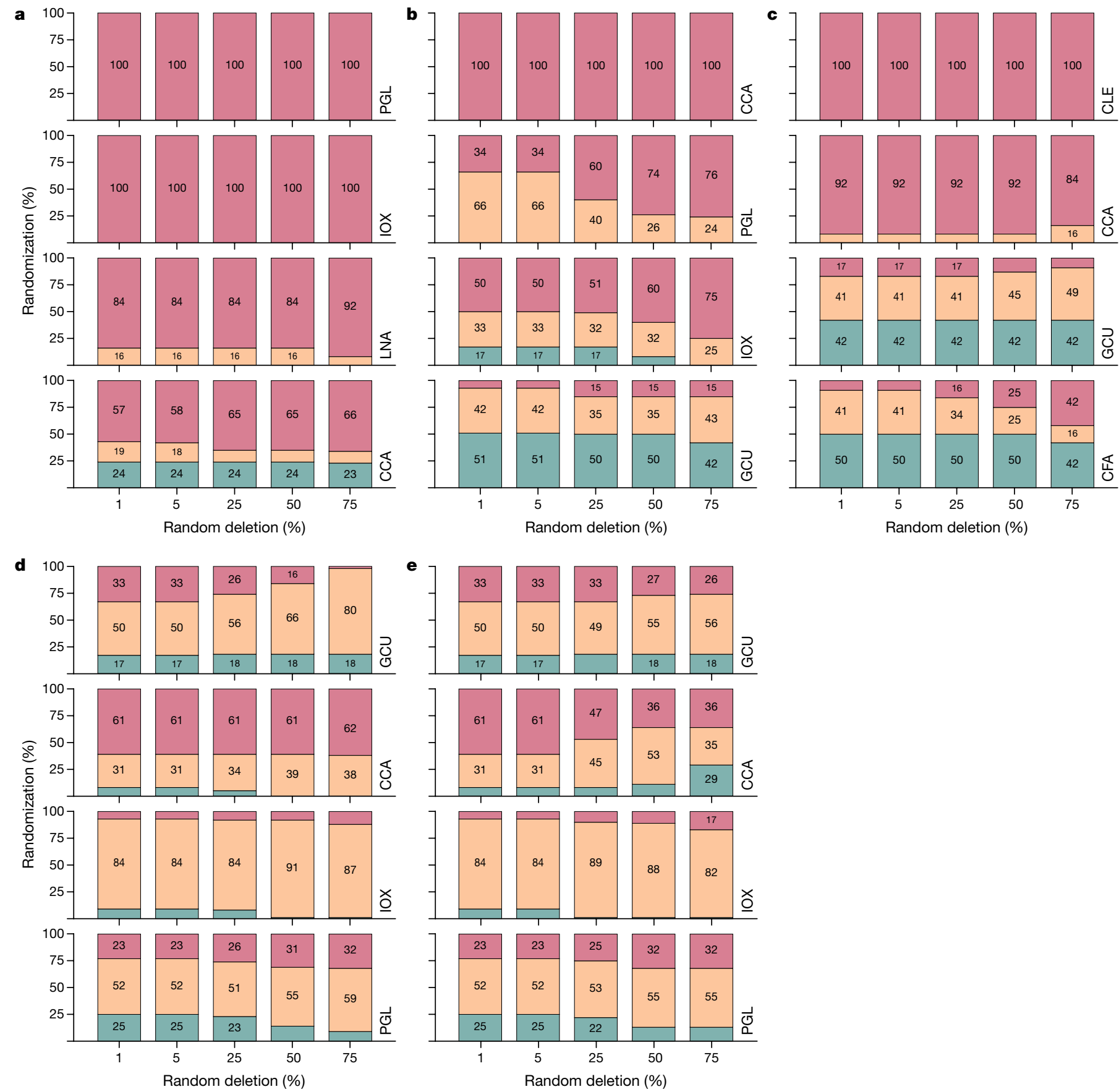

Fig. 2 | Example effects of random deletions of fishing effort data on exposure risk patterns. a-e, The percentage of randomized deletions from 100 repeats that resulted in a species exposure risk estimate occurring within the high (red), moderate (yellow) or low (green) risk category at each level of deletion $(1 \%, 5 \%, 25 \%, 50 \%$ or $75 \%)$ of fishing effort grid cells per sub-region. a, North Atlantic. b, Eastern Pacific Ocean. c, Southwest Indian Ocean. d, Northwest Oceania. e, Eastern Oceania. The map that shows the locations of sub-regions is provided in Supplementary Fig. 1. CCA, white shark (Carcharodon carcharias); CFA, silky shark (Carcharhinusfalciformis);

(NWS) is now removed, indicating that these few longline and purse seine vessels were not classified accurately in the GFW 2012-2016 data product. However, the GFW 2018 product does not show the reclassifications proposed off the southern Great Barrier Reef (GBR); therefore, further verifications are needed to correct those.

We agree that the space use hotspot for tiger shark (Galeocerdo cuvier) in Australia's NWS does not overlap with AIS-monitored longline
CLE, bull shark (Carcharhinus leucas); GCU, tiger shark (Galeocerdo cuvier); IOX, shortfin mako shark (Isurus oxyrinchus); LNA, porbeagle shark (Lamna nasus); PGL, blue shark (Prionace glauca). Overall, only 6 out of 36 speciesregion combinations (16.7\%) showed significant differences in the proportion of 100 randomizations per combination that each resulted in exposure risk falling within higher, moderate and lower risk categories when comparing $1 \%$ and $75 \%$ of random deletions of fishing effort data. Detailed summaries are provided in Supplementary Tables 1-7.

fishing effort in that area based on the GFW 2012-2016 data product that we used. Therefore, an important question raised ${ }^{2}$ is whether the reclassification of the gear types of 47 vessels directly affects the calculations of fishing exposure and our conclusions. In our paper ${ }^{1}$, the area (at the $1^{\circ} \times 1^{\circ}$ grid cell scale) covered by AIS longline fishing effort in Western Australia is $0.4 \%$ of the global coverage and the southern GBR area represents only $0.06 \%$. Within the Oceania region used in our 


\section{Matters arising}

paper, Western Australia comprises $2.2 \%$ and GBR $0.35 \%$. Therefore, the areas comprising reclassifications provide a minor contribution to the spatial overlap and FEI values that we calculated not only globally but also within the Oceania region.

To check our results within the global context, we compared the spatial overlap of sharks and longline fishing effort in our paper ${ }^{1}$ with the new releases of GFW fishing effort data that have been made available since the publication of our paper (Fig. 1 and Extended Data Table 1). The new releases of GFW data take into account refinements in the algorithms used to classify vessel (gear) types and new knowledge from metadata on the gear of the vessels. We find that-globally-the GFW longline fishing patterns remain almost identical (Fig.1). Spatial overlap and exposure patterns also remain very similar. For example, the mean monthly spatial overlap estimate for all oceans of $24 \%$ presented in our paper is within the range (19-29\%) calculated using the new GFW data (Extended Data Table 1). In the Exclusive Economic Zone (EEZ) of Australia, the number of FEI grid cells actually increased from 151 to 155 between the original GFW data (2012-2016) and the updated 2012-2018 data, whereas in the EEZ of western Australia the number decreased from 50 to 37 grid cells between datasets. For Oceania (including Australian shelf waters), the spatial overlap of $24 \%$ in our paper is within the $17-25 \%$ range estimated with newer GFW data. We also find that the spatial overlap-FEI plots remain largely unchanged across the four GFW datasets (Extended Data Fig. 1). Therefore, the NWS vessel reclassifications are minor and affect a single hotspot for tiger sharks.

To address the potential issue raised by Harry and Braccini ${ }^{2}$ that longline vessel reclassifications occur more broadly and may alter results in substantial ways, we randomly deleted $1 \%$ of grid cells that contained longline fishing effort per ocean region to simulate reclassification of longline vessels to other gears and this randomization was repeated 100 times. This is more extreme than simply removing a few individual vessels because each replicate removes $1 \%$ of grid cells, each comprising summed fishing effort from single or multiple vessels. Extended Data Table 2 shows that of the 30 species-region pairs available for analysis, we found that only $7 \%$ of species-region pairs changed from highest (red) to moderate (yellow) fishing exposure risk, whereas 3\% changed from moderate to highest risk after the simulated 'reclassification'. We repeated this for 5\% random deletions. Even at this much higher level of longline gear reclassification, we obtained the same results (Extended Data Table 3).

To examine what level of localized reclassification may lead to a breakdown of the fishing exposure risk patterns that we found, we randomly deleted $1 \%, 5 \%, 25 \%, 50 \%$ and $75 \%$ of fishing effort grid cells within five sub-regions (Supplementary Fig. 1) and recalculated spatial overlap and FEI for four key species per sub-region (Fig. 2 and Supplementary Methods). Results reveal no change in patterns of overlap and FEI for the four key species for the random deletion of up to $75 \%$ of data for regions in which shark spatial densities and fishing effort were both high and spatially extensive (for example, the North Atlantic (Fig. 2a)). Patterns change marginally above deletion of $25 \%$ of data for some species in other sub-regions in which fewer vessels and sharks were tracked (Fig. 2b, d). Seasonal patterns in exposure risk also remained largely unchanged albeit with larger differences at higher levels of fishing effort deletions (Supplementary Fig. 2). Levels of inaccuracy as high as we simulated in these tests are not evident in worldwide GFW vessel classifications ${ }^{3}$. Clearly, our results are not as sensitive to minor changes in sub-region vessel reclassifications as suggested by Harry and Braccini².

Harry and Braccini $^{2}$ emphasize that regional results should not be overlooked within a global-scale study. We agree, which is why we provided region-specific results for individual species that were discussed in detail in our paper ${ }^{1}$ (see supplementary results and discussion 2.6 of ref. $^{1}$ ), in which each regional analysis was informed by regional experts among the authorship, including for Western Australia. Although continued refinements to fishing gears ascribed to AIS-monitored vessels in the GFW dataset are useful, we disagree with Harry and Braccini ${ }^{2}$ about the levels of fishing threatening large sharks in Australia's NWS where we identified the space use hotspot for tiger sharks. They incorrectly assert that longline fishing has not occurred for two decades in Australia's NWS ${ }^{2}$. Longline and gillnet fishing not only occurred historically in the NWS and offshore to the boundary of Australia's EEZ ${ }^{5}$, but also continues to occur there through illegal, unreported and unregulated fishing ${ }^{6-8}$ by vessels that are not equipped with or that do not use AIS, which we discussed in our paper ${ }^{1}$. Illegal, unreported and unregulated fishers are known to target sharks-including tiger sharks ${ }^{9}$ - for fins, an ongoing threat that has been a major problem in Australia's NWS ${ }^{7}$, which overlaps with the tiger shark hotspot ${ }^{8}$. Therefore, it cannot be discounted that the shark hotspot overlaps with non-AIS monitored fishing activity, especially as more than 0.5 million $\mathrm{km}^{2}$ of the NWS remains open to commercial shark fishing ${ }^{10}$. Furthermore, the 55-year-long shark control program along $1,760 \mathrm{~km}$ of coastal northeastern Australia shows a long-term decline in the abundance of tiger sharks ${ }^{11,12}$; this is a region with movement and genetic connectivity with tiger sharks of the NWS ${ }^{13}$. In our view, Harry and Braccini ${ }^{2}$ overlook existing threats to tiger sharks and other shark species from fishing in the NWS.

As a consequence, we disagree with the opinion that existing science-based management has been undermined by our results or conclusions. Rather, in our paper ${ }^{1}$ we highlighted specifically the need to incorporate tracking and other spatial data into scientific assessments. However, this should not be misinterpreted as spatial data representing a regional management tool to replace assessments that rely on other types of data, such as time-series catch data. Indeed, a review ${ }^{14}$ cited in our paper identifies examples in which marine animal tracking and space use data informed policy, and it is evident that these data were never used in isolation from existing management regimes or complementary scientific assessments. Our paper ${ }^{1}$ emphasizes the need for a holistic approach to shark management that should also incorporate dynamic, spatial data.

\section{Reporting summary}

Further information on experimental design is available in the Nature Research Reporting Summary linked to this paper.

\section{Data availability}

Data used to prepare the maps (shark relative spatial density, longline-fishing effort and shark-longline-fishing overlap and FEI) are available on GitHub (https://github.com/GlobalSharkMovement/ GlobalSpatialRisk).

\section{Code availability}

Code used to prepare the maps (shark relative spatial density, longline-fishing effort and shark-longline-fishing overlap and FEI) is available on GitHub (https://github.com/GlobalSharkMovement/ GlobalSpatialRisk).

Queiroz, N. et al. Global spatial risk assessment of sharks under the footprint of fisheries. Nature 572, 461-466 (2019).

2. Harry, A., Braccini, M. Caution over the use of ecological big data for conservation. Nature https://doi.org/10.1038/s41586-021-03463-w (2021).

3. Kroodsma, D. A. et al. Tracking the global footprint of fisheries. Science 359, 904-908 (2018).

4. European Commission. European Union Fleet Register. version 1.0.8.8 https://webgate. ec.europa.eu/fleet-europa/index_en (accessed 10 April 2020).

5. Stevens, J. D. Management of shark fisheries in Northern Australia. FAO Fisheries Technical Paper No. 378/2 http://www.fao.org/3/×2097e/X2097E20.htm\#ch16 (FAO, 1999).

6. Griffiths, S., Edgar, S., Wang, Y.-G. \& Salini, J. Calculating recent foreign fishing vessel numbers using established estimators based on Coastwatch surveillance and apprehension data. Project Number 2007/836 (Australian Fisheries Management Authority 2008). 
7. Field, I. C., Meekan, M. G., Buckworth, R. C. \& Bradshaw, C. J. A. Protein mining the world's oceans: Australasia as an example of illegal expansion-and-displacement fishing. Fish Fish. 10, 323-328 (2009).

8. Australian Fisheries Management Authority. Indonesian illegal fisher apprehended off Darwin convicted. https://www.afma.gov.au/news-media/media-releases/indonesianillegal-fisher-apprehended-darwin-convicted (Australian Border Force and Australian Fisheries Management Authority, 1 November 2019).

9. Marshall, L. The Fin Blue Line: quantifying Fishing Mortality using Shark Fin Morphology. PhD Thesis, Univ. of Tasmania (2011).

10. Braccini, M., Molony, B. \& Blay, N. Patterns in abundance and size of sharks in northwestern Australia: cause for optimism. ICES J. Mar. Sci. 77, 72-82 (2020).

11. Roff, G., Brown, C. J., Priest, M. A. \& Mumby, P. J. Decline of coastal apex shark populations over the past half century. Commun. Biol. 1, 223 (2018).

12. Ferreira, L. C. \& Simpfendorfer, C. Galeocerdo cuvier. e.T39378A2913541 (The IUCN Red List of Threatened Species, 2019).

13. Pirog, A. et al. Genetic population structure and demography of an apex predator, the tiger shark Galeocerdo cuvier. Ecol. Evol. 9, 5551-5571 (2019).

14. Hays, G. C. et al. Translating marine animal tracking data into conservation policy and management. Trends Ecol. Evol. 34, 459-473 (2019).

Acknowledgements Funding support was provided by the Natural Environment Research Council (NERC) (NE/RO0997/X/1), European Research Council (ERC-AdG-2019 883583 OCEAN DEOXYFISH) (D.W.S.), Fundação para a Ciência e a Tecnologia CEECIND/02857/2018 (N.Q.) and PTDC/BIA-COM/28855/2017 (M.V.). This research is part of the Global Shark Movement Project (http://globalsharkmovement.org/).

Author contributions N.Q. and D.W.S. planned the data analysis. N.Q. led the data analysis with contributions from M.V. and D.W.S. N.E.H. contributed analysis tools. D.W.S. led the manuscript writing with contributions from N.Q., N.E.H. and all authors. Seven of the original authors were not included in the Reply authorship; two authors retired from science and the remaining five although supportive of our Reply, declined to join the authorship due to potential conflicts of interest with the authors of the Comment and/or their institutions.

Competing interests The authors declare no competing interests.

\section{Additional information}

Supplementary information The online version contains supplementary material available at https://doi.org/10.1038/s41586-021-03464-9.

Correspondence and requests for materials should be addressed to D.W.S.

Reprints and permissions information is available at http://www.nature.com/reprints.

Publisher's note Springer Nature remains neutral with regard to jurisdictional claims in published maps and institutional affiliations.

\section{(C) The Author(s), under exclusive licence to Springer Nature Limited 2021}

${ }^{1}$ Centro de Investigação em Biodiversidade e Recursos Genéticos/Research Network in Biodiversity and Evolutionary Biology, Campus Agrário de Vairão, Universidade do Porto, Vairão, Portugal. ${ }^{2}$ Marine Biological Association of the United Kingdom, Plymouth, UK. ${ }^{3}$ Departamento de Biologia, Faculdade de Ciências da Universidade do Porto, Porto, Portugal. ${ }^{4}$ UWA Oceans Institute, Indian Ocean Marine Research Centre, University of Western Australia, Crawley, Western Australia, Australia. ${ }^{5}$ School of Biological Sciences, University of Western Australia, Crawley, Western Australia, Australia. ${ }^{6}$ Spanish Institute of Oceanography, Santa Cruz de Tenerife, Spain. ${ }^{7}$ Abercrombie and Fish, Port Jefferson Station, NY, USA. ${ }^{8}$ Marine Biology and Aquaculture Unit, College of Science and Engineering, James Cook University, Cairns, Queensland, Australia. ${ }^{9}$ Institute of Natural and Mathematical Sciences, Massey University, Palmerston North, New Zealand. ${ }^{10}$ Universidade Federal Rural de Pernambuco (UFRPE), Departamento de Pesca e Aquicultura, Recife, Brazil. "MARE, Marine and Environmental Sciences Centre, Instituto Politécnico de Leiria, Peniche, Portugal. ${ }^{12}$ MARE, Laboratório Marítimo da Guia, Faculdade de Ciências da Universidade de Lisboa, Cascais, Portugal. ${ }^{13}$ Institute of Marine Research (IMAR), Departamento de Oceanografia e Pescas, Universidade dos Açores, Horta, Portugal. ${ }^{14}$ Okeanos - Departamento de Oceanografia e Pescas, Universidade dos Açores, Horta, Portugal. ${ }^{15}$ Department of Environmental Affairs, Oceans and Coasts Research, Cape Town, South Africa. ${ }^{16}$ Large Marine Vertebrates Research Institute Philippines, Jagna, Philippines. ${ }^{17}$ Fins Attached Marine Research and Conservation, Colorado Springs, CO, USA. ${ }^{18}$ Programa Restauración de Tortugas Marinas PRETOMA, San José, Costa Rica. ${ }^{19}$ MigraMar, Olema, CA, USA. ${ }^{20}$ Institut de Recherche pour le Développement, UMR MARBEC (IRD, Ifremer, Univ. Montpellier, CNRS), Sète, France. ${ }^{21}$ Biology Department, University of Massachusetts Dartmouth, Dartmouth, MA, USA. ${ }^{22}$ Red Sea Research Center, Division of Biological and Environmental Science and Engineering, King Abdullah University of Science and Technology, Thuwal, Saudi Arabia. ${ }^{23}$ Fundación Malpelo y Otros Ecosistemas Marinos, Bogota, Colombia. ${ }^{24}$ Hopkins Marine Station of Stanford University, Pacific Grove, CA, USA. ${ }^{25}$ Department of Biological Sciences,
Florida International University, North Miami, FL, USA. ${ }^{26}$ Instituto de Ciências do Mar, Universidade Federal do Ceará, Fortaleza, Brazil. ${ }^{27}$ School of Fishery and Aquatic Sciences, University of Washington, Seattle, WA, USA. ${ }^{28}$ Biology Department, Woods Hole Oceanographic Institution, Woods Hole, MA, USA. ${ }^{29}$ Shark Research and Conservation Program, Cape Eleuthera Institute, Eleuthera, Bahamas. ${ }^{30}$ University of Exeter, Exeter, UK. ${ }^{31}$ South Atlantic Environmental Research Institute, Stanley, Falkland Islands. ${ }^{32}$ Department of Biological Sciences, The Guy Harvey Research Institute, Nova Southeastern University, Dania Beach, FL, USA. ${ }^{33}$ School of Natural Resources, University of Missouri, Columbia, MO, USA. ${ }^{34}$ Life and Environmental Sciences, University of Iceland, Reykjavik, Iceland. ${ }^{35}$ School of Marine Science and Policy, University of Delaware, Lewes, DE, USA. ${ }^{36}$ Massachusetts Division of Marine Fisheries, New Bedford, MA, USA. ${ }^{37}$ Marine Research Facility, Jeddah, Saudi Arabia. ${ }^{38} \mathrm{PSL}$, Labex CORAIL, CRIOBE USR3278 EPHE-CNRS-UPVD, Papetoai, French Polynesia. ${ }^{39}$ Agence de Recherche pour la Biodiversité à la Réunion (ARBRE), Réunion, Marseille, France. ${ }^{40}$ Institut de Recherche pour le Développement, UMR 228 ESPACE-DEV, Réunion, Marseille, France. ${ }^{41}$ Save Our Seas Foundation-D'Arros Research Centre (SOSF-DRC), Geneva, Switzerland. ${ }^{42}$ South African Institute for Aquatic Biodiversity (SAIAB), Grahamstown, South Africa. ${ }^{43}$ Department of Fisheries Evaluation, Fisheries Research Division, Instituto de Fomento Pesquero (IFOP), Valparaíso, Chile. ${ }^{44}$ School of Biological, Earth and Environmental Sciences, University College Cork, Cork, Ireland. ${ }^{45}$ MaREI Centre, Environmental Research Institute, University College Cork, Cork, Ireland. ${ }^{46}$ College of Science and Engineering, Flinders University, Adelaide, South Australia, Australia. ${ }^{47}$ Department of Conservation, Auckland, New Zealand. ${ }^{48}$ South African Institute for Aquatic Biodiversity, Geological Sciences, UKZN, Durban, South Africa. ${ }^{49}$ Direccion Parque Nacional Galapagos, Puerto Ayora, Galapagos, Ecuador. ${ }^{50}$ Australian Institute of Marine Science, Indian Ocean Marine Research Centre (UWA), Crawley Western Australia, Crawley, Australia. ${ }^{51}$ Department of Fish and Wildlife Conservation, Virginia Tech, Blacksburg, VA, USA. ${ }^{52} \mathrm{OCEARCH}$, Park City, Utah, USA. ${ }^{53}$ Bedford Institute of Oceanography, Dartmouth, Nova Scotia, Canada. ${ }^{54}$ National Institute of Water and Atmospheric Research, Wellington, New Zealand. ${ }^{55}$ Beneath the Waves, Herndon, VA, USA. ${ }^{56}$ Rosenstiel School of Marine and Atmospheric Science, University of Miami, Miami, FL, USA. ${ }^{57}$ Oceans Research, Mossel Bay, South Africa. ${ }^{58}$ Department of Ichthyology and Fisheries Science, Rhodes University, Grahamstown, South Africa. ${ }^{59}$ SARDI Aquatic Sciences, Adelaide, South Australia, Australia. ${ }^{60}$ Zoological Society of London, London, UK. ${ }^{61}$ Galapagos Whale Shark Project, Puerto Ayora, Galapagos, Ecuador. ${ }^{62}$ Griffith Centre for Coastal Management, Griffith University School of Engineering, Griffith University, Gold Coast, Queensland, Australia. ${ }^{63}$ Bimini Biological Field Station, South Bimini, Bahamas. ${ }^{64}$ Smithsonian Tropical Research Institute, Panama City, Panama. ${ }^{65}$ Leonard and Jayne Abess Center for Ecosystem Science and Policy, University of Miami, Coral Gables, FL, USA. ${ }^{66}$ Galapagos Science Center, San Cristobal, Galapagos, Ecuador. ${ }^{67}$ Universidad San Francisco de Quito, Quito, Ecuador. ${ }^{68}$ Blue Water Marine Research, Tutukaka, New Zealand. ${ }^{69}$ University of QueenslandBrisbane, Queensland, Australia. ${ }^{70}$ Microwave Telemetry, Columbia, MD, USA. ${ }^{71}$ Pelagios-Kakunja, La Paz, Mexico. ${ }^{72}$ Mote Marine Laboratory, Center for Shark Research, Sarasota, FL, USA. ${ }^{73}$ Biological Sciences, University of Windsor, Windsor, Ontario, Canada. ${ }^{74}$ Cape Research and Diver Development, Simon's Town, South Africa. ${ }^{75}$ Institute of Zoology, Zoological Society of London, London, UK. ${ }^{76}$ Centre for Sustainable Aquatic Ecosystems, Harry Butler Institute, Murdoch University, Perth, Western Australia, Australia. ${ }^{77}$ Dyer Island Conservation Trust, Western Cape, South Africa. ${ }^{78}$ Blue Wilderness Research Unit, Scottburgh, South Africa. ${ }^{79}$ University of California Davis, Davis, CA, USA. ${ }^{80}$ Cape Research Centre, South African National Parks, Steenberg, South Africa. ${ }^{81}$ Shark Spotters, Fish Hoek, South Africa. ${ }^{82}$ Institute for Communities and Wildlife in Africa, Department of Biological Sciences, University of Cape Town, Rondebosch, South Africa. ${ }^{83}$ Western Cape Department of Agriculture, Veterinary Services, Elsenburg, South Africa. ${ }^{84}$ Departamento de Biologia Marinha, Universidade Federal Fluminense (UFF), Niterói, Brazil. ${ }^{85}$ Department of Zoology, University of Cambridge, Cambridge, UK. ${ }^{86}$ Atlantic White Shark Conservancy, Chatham, MA, USA. ${ }^{87}$ Fisheries and Aquaculture Centre, Institute for Marine and Antarctic Studies, University of Tasmania, Hobart, Tasmania, Australia. ${ }^{88}$ Pontificia Universidad Católica del Ecuador Sede Manabi, Portoviejo, Ecuador. ${ }^{89}$ Marine Megafauna Foundation, Truckee, CA, USA. ${ }^{90}$ Conservation and Fisheries Department, Ascension Island Government, Georgetown, Ascension Island, UK. ${ }^{91}$ Marine Conservation Society Seychelles, Victoria, Seychelles. ${ }^{92} \mathrm{CORDIO}$, East Africa, Mombasa, Kenya. ${ }^{93}$ Upwell, Monterey, CA, USA. ${ }^{94}$ Department of Zoology and Institute for Coastal and Marine Research, Nelson Mandela University, Port Elizabeth, South Africa. ${ }^{95}$ National Institute of Polar Research, Tachikawa, Tokyo, Japan. ${ }^{96}$ SOKENDAI (The Graduate University for Advanced Studies), Tachikawa, Tokyo, Japan. ${ }^{97}$ Centre for Ecology and Conservation, University of Exeter, Penryn, UK. ${ }^{98}$ Department of Biological Sciences, University of Rhode Island, Kingston, RI, USA. ${ }^{99}$ Department of Oceanography and Environment, Fisheries Research Division, Instituto de Fomento Pesquero (IFOP), Valparaíso, Chile. ${ }^{100}$ Department of Biological Sciences, Macquarie University, Sydney, New South Wales, Australia. ${ }^{101}$ School of Life and Environmental Sciences, Deakin University, Geelong, Victoria, Australia. ${ }^{102} \mathrm{AZTI}$ - Marine Research, Pasaia, Spain. ${ }^{103}$ IKERBASQUE, Basque Foundation for Science, Bilbao, Spain. ${ }^{104}$ Instituto de Fisica Interdisciplinar y Sistemas Complejos, Consejo Superior de Investigaciones Cientificas, University of the Balearic Islands, Palma de Mallorca, Spain. ${ }^{105}$ Wildlife Conservation Research Unit, Department of Zoology, University of Oxford, Tubney, UK. ${ }^{106}$ Ocean and Earth Science, National Oceanography Centre Southampton, University of Southampton, Southampton, UK. ${ }^{107}$ Centre for Biological Sciences, University of Southampton, Southampton, UK. ${ }_{\text {e-mail: dws@mba.ac.uk }}$ 


\section{Matters arising}
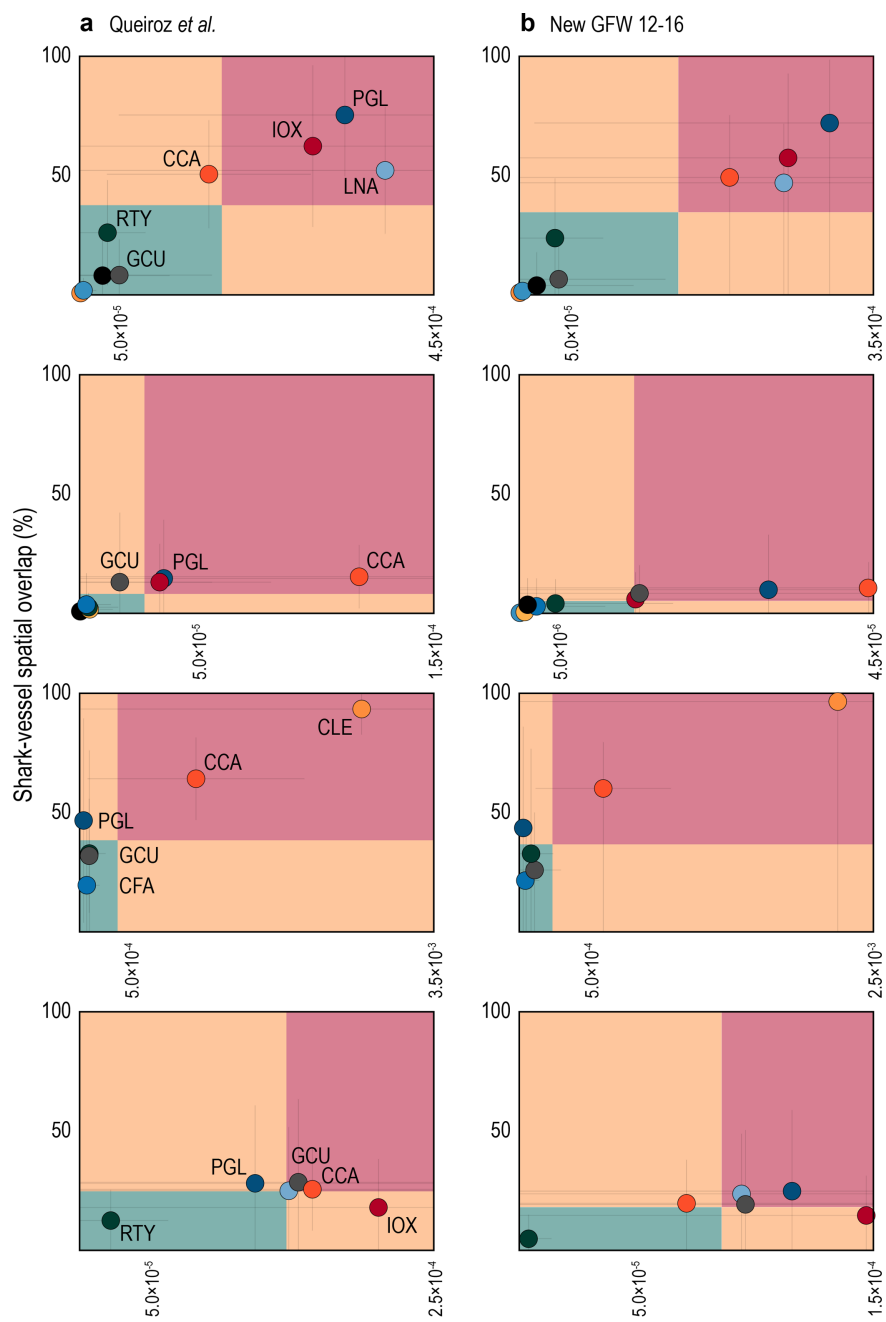
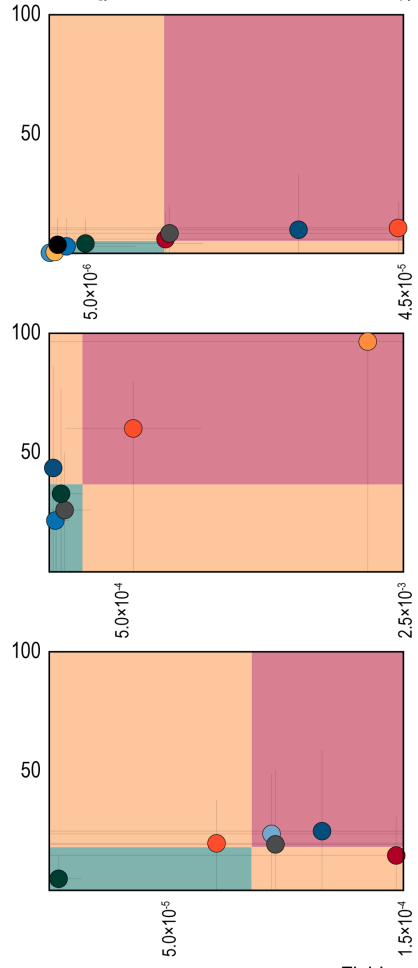

Fishing exp
Extended Data Fig. 1 | Comparing shark exposure risk between AIS longline fishing effort datasets. a-d, Estimated exposure risk of sharks to capture by GFW AIS longline fishing effort across ocean regions for Queiroz et al. ${ }^{1}$ (a) compared with three improved data releases since the paper was published (b-d).
C New GFW 12-18
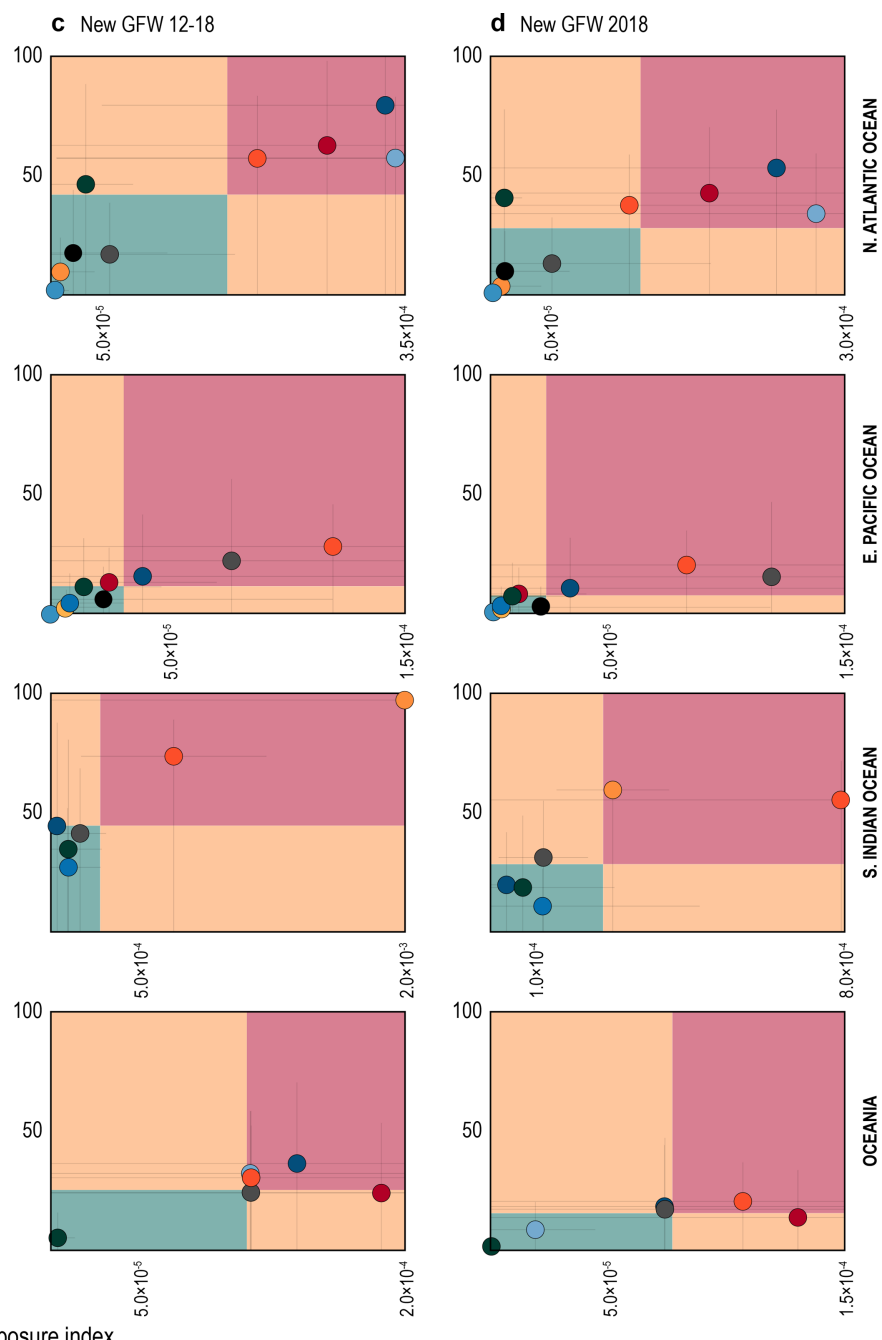

The plots show minor effects of any changes on estimates of shark exposure risk from AIS longline fishing effort and confirm the global results and conclusions of our paper. a, Data from Queiroz et al. ${ }^{1} . \mathbf{b}$, Data from GWF 2012-2016. c, Data from GWF 2012-2018. d, Data from GWF 2018. 
Extended Data Table 1 | Mean monthly spatial overlap estimates (\%) of pelagic shark space use and AIS longline fishing effort for different AIS datasets

\begin{tabular}{|c|c|c|c|c|c|c|c|c|c|}
\hline & $N$ tags & \multicolumn{2}{|c|}{ Queiroz et al. } & \multicolumn{2}{c|}{ New GFW 2012-16 } & \multicolumn{2}{c|}{ New GFW 2012-18 } & \multicolumn{2}{c|}{ New GFW 2018} \\
\hline & & mean & S.D. & mean & S.D. & mean & S.D. & Mean & S.D. \\
\hline Global & 1611 & 24.37 & 33.08 & 21.98 & 32.20 & 28.93 & 34.44 & 18.98 & 25.79 \\
\hline N Atlantic & 649 & 37.41 & 38.60 & 34.62 & 37.58 & 42.00 & 38.21 & 27.92 & 29.09 \\
\hline E Pacific & 588 & 7.80 & 15.99 & 5.18 & 13.29 & 11.38 & 19.14 & 7.53 & 14.89 \\
\hline SW Indian & 153 & 38.31 & 35.31 & 36.69 & 35.14 & 44.53 & 36.95 & 28.38 & 28.20 \\
\hline Oceania & 151 & 24.42 & 27.21 & 18.13 & 25.18 & 25.32 & 29.04 & 15.61 & 23.21 \\
\hline
\end{tabular}




\section{Matters arising}

Extended Data Table 2 | Effect of $1 \%$ random deletion of fishing effort grid cells within each region on risk exposure estimates

\begin{tabular}{|l|l|l|l|l|l|l|l|l|}
\hline & N Atlantic & E Pacific & \multicolumn{2}{l|}{ SW Indian } & \multicolumn{2}{l|}{ Oceania } \\
\hline Main species & Before & After & Before & After & Before & After & Before & After \\
\hline Prionace glauca & & & & & & & \\
\hline Isurus oxyrinchus & & & & & & & & \\
\hline Lamna nasus & & & & & & & \\
\hline Carcharodon carcharias & & & & & & & & \\
\hline Galeocerdo cuvier & & & & & & & & \\
\hline Sphyrna spp. & & & & & & & & \\
\hline Rhincodon typus & & & & & & & & \\
\hline Carcharinus longimanus & & & & & & & & \\
\hline Carcharhinus falciformis & & & & & & & & \\
\hline Carcharhinus leucas & & & & & & & & \\
\hline Lamna ditropis & & & & & & & & \\
\hline
\end{tabular}

The results show minor effects of substantial removal of longline fishing effort. Before/after denotes before/after deletion. Red denotes the highest risk exposure category, green indicates the least risk. The 'after' colour represents the category with the highest percentage of occurrence after 100 randomizations. No change in colour between before/after indicates no change in spatial overlap and exposure risk of species from AIS longline fishing effort. White indicates that no tracking data are available to undertake analysis. There are no changes from high to low, or vice versa. 
Extended Data Table 3 | Effect of $5 \%$ random deletion of fishing effort grid cells within each region on risk exposure estimates

\begin{tabular}{|l|l|l|l|l|l|l|l|l|}
\hline & N Atlantic & E Pacific & \multicolumn{2}{l|}{ SW Indian } & \multicolumn{2}{l|}{ Oceania } \\
\hline Main species & Before & After & Before & After & Before & After & Before & After \\
\hline Prionace glauca & & & & & & & \\
\hline Isurus oxyrinchus & & & & & & & \\
\hline Lamna nasus & & & & & & & & \\
\hline Carcharodon carcharias & & & & & & & & \\
\hline Galeocerdo cuvier & & & & & & & & \\
\hline Sphyrna spp. & & & & & & & & \\
\hline Rhincodon typus & & & & & & & & \\
\hline Carcharinus longimanus & & & & & & & & \\
\hline Carcharhinus falciformis & & & & & & & & \\
\hline Carcharhinus leucas & & & & & & & & \\
\hline Lamna ditropis & & & & & & & & \\
\hline
\end{tabular}

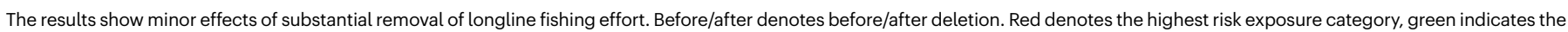
least risk. The 'after' colour represents the category with the highest percentage of occurrence after 100 randomizations. No change in colour between before/after indicates no change in

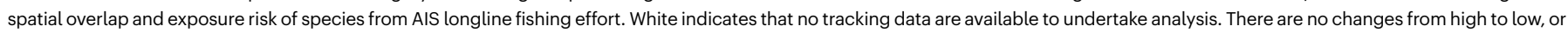
vice versa. 


\section{Author Queries}

Journal: Nature

Paper: s41586-021-03464-9

Title:Reply to: Caution over the use of ecological big data for conservation

\section{AUTHOR:}

The following queries have arisen during the editing of your manuscript. Please answer by making the requisite corrections directly in thee.proofing tool rather than marking them up on thePDF. This will ensure that your correctionsare incorporated accurately and that your paper is published as quickly as possible.

\begin{tabular}{|c|c|}
\hline $\begin{array}{l}\text { Query } \\
\text { Reference }\end{array}$ & Reference \\
\hline Q1 & $\begin{array}{l}\text { Please check your article carefully, coordinate with any co-authors and enter all final edits clearly in the } \\
\text { eproof, remembering to save frequently. Once corrections are submitted, we cannot routinely make } \\
\text { further changes to the article. }\end{array}$ \\
\hline Q2 & $\begin{array}{l}\text { Note that the eproof should be amended in only one browser window at any one time; otherwise } \\
\text { changes will be overwritten. }\end{array}$ \\
\hline Q3 & $\begin{array}{l}\text { Author surnames have been highlighted. Please check these carefully and adjust if the first name or } \\
\text { surname is marked up incorrectly. Note that changes here will affect indexing of your article in public } \\
\text { repositories such as PubMed. Also, carefully check the spelling and numbering of all author names } \\
\text { and affiliations, and the corresponding email address(es). }\end{array}$ \\
\hline Q4 & $\begin{array}{l}\text { You cannot alter accepted Supplementary Information files except for critical changes to scientific } \\
\text { content. If you do resupply any files, please also provide a brief (but complete) list of changes. If these } \\
\text { are not considered scientific changes, any altered Supplementary files will not be used, only the } \\
\text { originally accepted version will be published. }\end{array}$ \\
\hline Q5 & $\begin{array}{l}\text { When you receive the eproof link, please check that the display items are as follows (ms no: 2019-11- } \\
\text { 17580): Figs (black and white); } 2 \text { (colour); Tables: None; Boxes: None; Extended Data display items: } \\
\text { Figs 1-3, Tables 1; SI (including reporting summary): yes. The eproof contains the main-text figures } \\
\text { edited by us and (if present) the Extended Data items (unedited except for the legends) and the } \\
\text { Supplementary Information (unedited). Please note that the eproof should be amended in only one } \\
\text { browser window at any one time, otherwise changes will be overwritten. Please check the edits to all } \\
\text { main-text figures very carefully, and ensure that any error bars in the figures are defined in the figure } \\
\text { legends. Extended Data items may be revised only if there are errors in the original submissions. If you } \\
\text { need to revise any Extended Data items please upload these files when you submit your corrections } \\
\text { to this preproof. }\end{array}$ \\
\hline Q6 & $\begin{array}{l}\text { The Extended Data Tables have been replaced with the resupplied tables, please check and confirm that it is } \\
\text { correct that Extended Data Tables } 2 \text { and } 3 \text { are identical, and that no differences were found between } 1 \% \text { and } \\
5 \% \text { deletion. If this is not correct, please could you resupply the incorrect table as TIFF or JPEG. }\end{array}$ \\
\hline
\end{tabular}




\section{Reporting Summary}

Nature Research wishes to improve the reproducibility of the work that we publish. This form provides structure for consistency and transparency in reporting. For further information on Nature Research policies, see our Editorial Policies and the Editorial Policy Checklist.

\section{Statistics}

For all statistical analyses, confirm that the following items are present in the figure legend, table legend, main text, or Methods section.

n/a Confirmed

$\square \bigotimes$ The exact sample size $(n)$ for each experimental group/condition, given as a discrete number and unit of measurement

$\square$ \ A statement on whether measurements were taken from distinct samples or whether the same sample was measured repeatedly

$\square$ The statistical test(s) used AND whether they are one- or two-sided

$\square$ Only common tests should be described solely by name; describe more complex techniques in the Methods section.

Х $\square$ A description of all covariates tested

$\square$ \A description of any assumptions or corrections, such as tests of normality and adjustment for multiple comparisons

$\square$ A full description of the statistical parameters including central tendency (e.g. means) or other basic estimates (e.g. regression coefficient)

$\bigotimes$ AND variation (e.g. standard deviation) or associated estimates of uncertainty (e.g. confidence intervals)

$\square$ For null hypothesis testing, the test statistic (e.g. $F, t, r$ ) with confidence intervals, effect sizes, degrees of freedom and $P$ value noted

Give $P$ values as exact values whenever suitable.

Х $\square$ For Bayesian analysis, information on the choice of priors and Markov chain Monte Carlo settings

Х $\square$ For hierarchical and complex designs, identification of the appropriate level for tests and full reporting of outcomes

$\triangle \square$ Estimates of effect sizes (e.g. Cohen's $d$, Pearson's $r$ ), indicating how they were calculated

Our web collection on statistics for biologists contains articles on many of the points above.

\section{Software and code}

Policy information about availability of computer code

Data collection No data collection software was used.

Data analysis All analyses described were undertaken in $\mathrm{R}$.

For manuscripts utilizing custom algorithms or software that are central to the research but not yet described in published literature, software must be made available to editors and reviewers. We strongly encourage code deposition in a community repository (e.g. GitHub). See the Nature Research guidelines for submitting code \& software for further information.

\section{Data}

Policy information about availability of data

All manuscripts must include a data availability statement. This statement should provide the following information, where applicable:

- Accession codes, unique identifiers, or web links for publicly available datasets

- A list of figures that have associated raw data

- A description of any restrictions on data availability

Data and source code used for preparing figure maps (shark relative spatial density, longline-fishing effort and shark-longline-fishing overlap and FEI) are available on GitHub (https://github.com/GlobalSharkMovement/GlobalSpatialRisk). 


\section{Field-specific reporting}

Please select the one below that is the best fit for your research. If you are not sure, read the appropriate sections before making your selection.

Life sciences $\quad \square$ Behavioural \& social sciences $\quad \square$ Ecological, evolutionary \& environmental sciences

For a reference copy of the document with all sections, see nature.com/documents/nr-reporting-summary-flat.pdf

\section{Ecological, evolutionary \& environmental sciences study design}

All studies must disclose on these points even when the disclosure is negative.

Study description

Research sample

Sampling strategy

Data collection

Timing and spatial scale

Data exclusions

Reproducibility

Randomization

Blinding
This study is a Reply to a Matters Arising comment on our original paper. To answer the points raised we re-plotted some of the original shark movements and fishing effort data in our paper which are fully described in figure and table legends and in the original paper. We also carried out new analyses using newer data releases of global longline fishing effort data that were freely available from Global Fishing Watch (www.globalfishingwatch.org).

In this Reply, the additional data used were the Global fishing Watch updated data release for AIS-monitored longline fishing effort in 2012-2018.

Global longline fishing effort data were obtained for automatic identification system (AIS) monitored vessels $>300$ gross tons.

Global longline fishing effort data for automatic identification system (AIS) monitored vessels $>300$ gross tons were made available by the Global Fishing Watch.

Global for 2012-2018.

No relevant data were excluded.

No experiments as such were conducted, rather our data are based on satellite tracked movements of individual pelagic sharks and fishing vessels.

Randomization procedures were used when removing 1, 5, 25, 50 and 75\% of the AIS data for breakpoint sensitivity analysis. Methods are fully described in the Reply and Supplementary Information files.

Blinding is not relevant to this type of study because our original data were based on movements of wild animals and fishing vessels.

Did the study involve field work? $\square$ Yes $\square$ No

\section{Reporting for specific materials, systems and methods}

We require information from authors about some types of materials, experimental systems and methods used in many studies. Here, indicate whether each material, system or method listed is relevant to your study. If you are not sure if a list item applies to your research, read the appropriate section before selecting a response.

\begin{tabular}{|c|c|}
\hline$n / a$ & Involved in the study \\
\hline Х & Antibodies \\
\hline め & Eukaryotic cell lines \\
\hline$\bigotimes$ & Palaeontology and archaeology \\
\hline$\bigotimes$ & Animals and other organisms \\
\hline$\bigotimes$ & Human research participants \\
\hline Х & Clinical data \\
\hline Х & Dual use research of concern \\
\hline
\end{tabular}

\begin{tabular}{l} 
Methods \\
\hline n/a
\end{tabular}

